\title{
MATRIZES DE INTERAÇÃO ENTRE CIÊNCIA E TECNOLOGIA E INOVAÇÕES AMBIENTAIS: UMA ABORDAGEM ENTRE OS PAÍSES DESENVOLVIDOS E EM DESENVOLVIMENTO (1990 - 2010)
}

\author{
Rosa Livia Montenegro (PPGE/UFJF) ${ }^{1}$ \\ Leonardo Costa Ribeiro (INMETRO) ${ }^{2}$ \\ Gustavo Britto (Cedeplar/UFMG) ${ }^{3}$
}

Indicação de área: Área 6 - Sistemas de inovação - nacional, setorial, tecnológico

Resumo: Os danos ambientais gerados pelas atividades econômicas e institucionais são preocupações recorrentes na atualidade. Nesse quesito, a inovação é o papel chave para que os países encontrem respostas diante dos desafios ambientais e, simultaneamente, promovam oportunidades para esses novos estímulos. Assim, o objetivo deste artigo é identificar quais áreas científicas e tecnológicas fomentaram o desenvolvimento tecnológico ambiental nos anos de 1990, 2000 e 2010, a partir da amostra de países que compõem os grupos BRICS e G7. Para atingir esse propósito, aplicação metodológica envolve a construção das Matrizes Tecnológicas por intermédio das patentes ambientais. O objetivo do uso desta técnica é identificar quais áreas científicas e tecnológicas proporcionam o desenvolvimento tecnológico ambiental. Além disso, a representação gráfica das matrizes possibilitará diferenciar as características de Sistemas Nacionais de Inovação maduros e imaturos. Os resultados revelam que a influência de tratados e os protocolos internacionais ambientais contribuíram para o aumento da produção de tecnologias ambientais no período em estudo, principalmente após o ano de 1990. Ademais, observou-se que alguns países em desenvolvimento, como a China, possuem semelhanças entre as assimetrias científicas e tecnológicas em relação aos países desenvolvidos.

Palavras Chave: Inovações Ambientais; Sistemas Nacionais de Inovação; Matrizes de Interação entre Ciência e Tecnologia

Abstract: Environmental damage caused by economic and institutional activities are a
recurring concern in debates on the subject. Innovation has a key role so that countries may
react against environmental challenges and, at the same time, enhance opportunities for new
stimuli. The aim of this article is identify scientific and technologic specific areas that foster the
environmental technologic development during the 1990s, 2000s and 2010s, in the countries
that constitute BRICS and G7 groups. To achieve this aim, the methodological application
involves the construction of Matrices of Interaction through the environmental patents. The
objective of using this technique is to identify which science and technology foster
environmental technology development. Futhermore, the representation of the matrices in
graphics allow differentiate characteristics of mature and immature National Systems of
Innovation. The results shows the influence of treaties and international environmental
protocols that contributed to increase the production of environmental technologies, especially
after the year 1990. Furthermore, developing countries, such as China, have similarities
between the scientific and technological asymmetries as well as developed countries.

Keywords: Environmental Innovation; National Systems of Innovation; Matrices of Interaction between Science and Technology

\footnotetext{
${ }^{1}$ Pós doutoranda no Programa de Pós Graduação em Economia (PPGE) pela Universidade Federal de Juiz de Fora (UFJF).

${ }^{2}$ Pesquisador do Instituto Nacional de Metrologia, Qualidade e Tecnologia (INMETRO).

${ }^{3}$ Professor Adjunto do Centro de Desenvolvimento e Planejamento Regional (CEDEPLAR) na Universidade Federal de Minas Gerais (UFMG).
} 
Classificação JEL: 033; 034

\section{Introdução}

Ao longo das últimas décadas, o desenvolvimento de políticas, a eliminação de barreiras comerciais e as inovações tecnológicas, especialmente no campo dos transportes, energia e das telecomunicações, abriram espaço para o aumento da internacionalização política e econômica. Além dos incentivos à industrialização, o progresso tecnológico em diversos setores na economia contribuiu para que os desdobramentos do crescimento econômico sobre o meio ambiente aumentassem. A atenção para com a sustentabilidade e o meio ambiente surgiu no início dos anos 70 e as questões políticas ambientais apareceram de forma proeminente na agenda acadêmica na década de 1980, época em que o debate deste tema emergiu no âmbito econômico (VAN DEN BERGH, 1999). Nesse contexto, as agressões ao meio ambiente se tornaram mais sérias e mais visíveis com o crescimento econômico e com a integração da economia mundial, tanto no centro quanto na periferia do capitalismo global.

Os problemas ambientais em questão referem-se àqueles que dificilmente respeitam as fronteiras dos países. São caracterizados por resíduos gerados pelos setores produtivos, pelos consumidores e espalham-se através do ar, da água para outros países e até globalmente, como no caso dos clorofluocarbonos (FREEMAN; SOETE, 2008). Em virtude do caráter internacional dos problemas ambientais, as metas para um mundo com mais sustentabilidade são requeridas para todos os países e exigirão uma ampla difusão de novas tecnologias, apoio de instituições e novos paradigmas de produção, consumo e descarte de resíduos. A natureza multidimensional, tanto dos problemas como das soluções, exige que organizações supranacionais, como as Nações Unidas, por exemplo, tenham um papel decisório nas mudanças e desafios ambientais que se acumulam globalmente (FREEMAN; SOETE, 2008).

Por esta razão, as mudanças de paradigmas requerem esforços sistemáticos para a resolução dos problemas que as tecnologias e sistemas produtivos não conseguem solucionar. Para a busca das respostas, a inovação é a palavra chave para que os países encontrem soluções diante dos desafios ambientais, e promovam oportunidades que surjam destes mesmos desafios. Nesse sentido, as inovações investigadas terão o aspecto ambiental e a definição baseada em Rennings (2000), que interpreta as inovações ambientais como inovações que caracterizam processos novos ou modificados, além de produtos, sistemas e métodos que beneficiam e contribuem para a preservação do meio ambiente.

Os incentivos à inovação e ao progresso tecnológico em diversos setores da economia são os mais variados possíveis. Diante do maior impacto de recursos energéticos renováveis e não renováveis, as economias têm respondido com o desenvolvimento de tecnologias alternativas (e.g. o desenvolvimento de energia eólica, agora usada indiretamente como meio de geração de energia elétrica e para a propulsão de navios). Outro exemplo é a exportação das tecnologias de energias solar e eólica que cresceram muito na última década, tanto entre países desenvolvidos como em países em desenvolvimento (OECD, 2010).

O grande desafio relacionado aos padrões tecnológicos atuais seria a criação de incentivos apropriados para o sistema econômico desenvolver tecnologias limpas e sustentáveis. Para esta mudança, espera-se que as escolhas e as ações dos consumidores convirjam para um conjunto de novas firmas e tecnologias capazes de criar e produzir uma nova seleção de produtos tecnológicos nos países (WINDRUM et al., 2009).

Para tanto, o presente artigo tem como principal objetivo mostrar o desenvolvimento tecnológico ambiental dos países que compõem o grupo BRICS ${ }^{4}$ e G7 nos anos de 1990, 2000 e

\footnotetext{
${ }^{4}$ Os países que compõem o grupo G7 são: Estados Unidos, Alemanha, Canadá, França, Itália, Japão, Reino Unido. Em relação ao grupo BRICS, este é composto pelos países: Brasil, Rússia, Índia, China e África do Sul.
} 
2010, a partir de seus diferentes estágios de Sistemas Nacionais de Inovação. Mais especificamente, este artigo procura responder: Quais seriam as assimetrias científicas $e$ tecnológicas que poderiam revelar os diferentes estágios de desenvolvimento tecnológico ambiental nos países sob estudo, nos anos de 1990, 2000 e 2010?

Nesse sentido, o trabalho divide-se, além desta introdução, em mais 4 (quatro) seções. A segunda seção trata da descrição e análise dos dados. A terceira parte aborda a estratégia empírica adotada e, em seguida, a quarta parte exibe os resultados das matrizes de interação entre ciência e tecnologia dos países que compõem os grupos BRICS e G7. Por fim, são tecidas as conclusões do artigo.

\section{Descrição e análise da base de dados}

A presente seção tem como objetivo apresentar a construção da base de dados utilizada para a elaboração das matrizes de interação entre C\&T. Para tanto, é necessário ressaltar que a principal proxy usada para captar as influências das inovações ambientais entre os países desenvolvidos e em desenvolvimento, são as patentes ambientais. $\mathrm{O}$ uso das patentes ambientais está pautado em uma grande diversidade de pesquisas empíricas que utilizam as mesmas como proxy para mensurar a capacidade tecnológica dos países, assim como para analisar o desenvolvimento da atividade inovativa ambiental nos Sistemas Nacionais de Inovação. Além disso, a originalidade e a riqueza de informações da base de dados permitirão analisar as principais classes tecnológicas ambientais. A investigação no âmbito nacional e temporal permitirá avaliar a dinâmica das tecnologias ambientais em direção a novos paradigmas tecnológicos.

\subsection{A Base de Dados Europeia (EPO), o Sistema de Classificação Internacional (IPC) e o Inventário Verde (Green Inventory)}

Para os procedimentos exploratórios e metodológicos utilizados no artigo, foram utilizadas as patentes com base no Escritório Europeu de Patentes (European Patent Office EPO), cujos dados foram extraídos da edição de abril de 2013 da EPO Patstat (nome oficial da base de dados de patentes mundiais da EPO). A base de dados PATSTAT foi desenvolvida especificamente para uso de organizações governamentais e instituições acadêmicas e possui uma atualização regular, realizada bianualmente (JOHNSTONE et al., 2008). Os documentos de patentes são categorizados, utilizando-se o sistema de Classificação Internacional de Patentes (IPC), a Classificação Europeia (ECLA) e a Classificação de Sistemas Nacionais de Patentes.

A escolha da base de patentes EPO foi pautada em sua representatividade, por permitir a construção de indicadores que podem ser estudados ao longo do tempo, pela identificação de patentes consideradas de 'alto padrão' e por fornecer uma ampla variedade de informações entre os inventores e depositantes (HAŠČIČ et al., 2010). Existem dois outros escritórios mundiais de patentes que também são importantes, a saber: o escritório americano (United States Patent and Trademark Office - USPTO) e o escritório japonês (Japan Patent Office - JPO). As diferenças entre eles consistem no processo de registro de uma patente, que pode ocasionar determinadas limitações quanto à comparabilidade das estatísticas de patentes entre países.

Além disso, a base de dados EPO abrange mais de 80 (oitenta) escritórios nacionais de patentes e contém mais de 60 milhões de documentos de patentes. Esses documentos são categorizados utilizando os códigos da Classificação Internacional de Patentes (ICP), 
desenvolvidos pela Organização Mundial de Propriedade Intelectual (WIPO) (DECHEZLEPRÊTRE et al., 2011).

Para a consecução e o tratamento da base de dados, delimitou-se em primeiro lugar o período de análise. O período proposto para a análise das caracterizações e desempenho das inovações ambientais entre os países refere-se aos anos de 1990, 2000 e 2010. Para tanto, o quantitativo de patentes ambientais depositadas registradas pelo banco de dados da base PATSTAT foi de 1.226.676 (em 1990), 1.780.282 (no ano 2000) e 2.247.078 patentes depositadas em 2010. Para o processamento das consultas e viabilização da construção da base de patentes ambientais, consideraram-se as patentes depositadas pela autoridade, pelo inventor e pelo titular de cada nação, que necessariamente contenham elementos indicativos de uma patente ambiental. Com isso, para a classificação das patentes ambientais utilizou-se o sistema IPC e as respectivas classes tecnológicas que caracterizam a patente como ambiental, possibilitando também sua identificação de acordo com as sete áreas estratégicas ${ }^{5}$, disponibilizadas pelo Inventário de Classificação de Patentes Verdes (IPC Green Inventory).

Por fim, uma das vantagens do uso das patentes do escritório EPO, utilizando a classificação do IPC Green Inventory refere-se às múltiplas possibilidades de análise dos resultados. Além disso, a construção da base de dados por grupos distintos de tecnologias permitirá analisar tecnologias específicas e distingui-las em relação ao seu uso pelos países desenvolvidos e em desenvolvimento. A seguir, será explorado o desenvolvimento tecnológico ambiental ao longo do tempo, de acordo com as patentes ambientais. A partir da elaboração dos indicadores destas patentes, será possível comparar as diferenças existentes entre a produção de tecnologias ambientais, analisando e identificando as amplas dimensões tecnológicas desenvolvidas ao longo do tempo.

\subsection{Análise exploratória das patentes ambientais: evolução e desempenho (1990-2010)}

As evidências quanto ao desempenho tecnológico ambiental obtiveram significativos efeitos a partir dos anos 90, que podem ser comparados segundo os resultados dos depósitos das patentes no Gráfico 1. Apesar de uma grande diferença observada de $84 \%$ entre o patenteamento das inovações em geral e o patenteamento ambiental, somente no ano de 2010, os resultados também mostram que houve um aumento do patenteamento ambiental, principalmente entre os anos de 1995 e 2000, com um crescimento de quase 50\% entre os respectivos anos. (GRÁFICO 1).

Vale ressaltar que o papel da regulação e dos acordos ambientais são fatores essenciais, tendo verdadeiros efeitos indutores (drivers) para as inovações ambientais, trazendo consigo o apoio ao desenvolvimento sustentável e a rápida difusão das tecnologias referentes. Além disso, o papel da regulamentação sobre as tecnologias ambientais é particularmente importante, seja por intermédio dos instrumentos baseados no mercado (por exemplo, com os impostos, licenças de permissão) ou por regulação direta (padrões de desempenho, certificados ambientais etc.) para indução das inovações ambientais.

Da mesma forma, enquanto que as características internas nacionais (nível educacional, tecnológico e econômico) e a elaboração das políticas internas (meio ambiente e tecnológica) parecem influenciar e direcionar o desenvolvimento tecnológico ambiental, o quadro político internacional também exerce um papel preponderante quanto ao desempenho tecnológico

\footnotetext{
${ }^{5}$ As sete áreas estratégicas são: (a) Produção de energia alternativa; (b) Transportes; (c) Conservação de energia; (d) Gestão de resíduos (e) Agricultura/silvicultura; (f) Aspectos administrativos, regulatórios e de projetos; (g) Geração de energia nuclear. Para maiores detalhes acessar : <http://www.wipo.int/classifications/ipc/en/est/>.
} 
ambiental mundial. Nesse quadro político, está envolvida uma série de acordos e tratados ambientais multilaterais que incentivam o desenvolvimento de conhecimentos interrelacionados às tecnologias ambientais com o objetivo de mitigar seus impactos ao meio ambiente (HAŠČIČ et al., 2010).

\section{GRÁFICO 1 - Evolução do depósito de patentes total e ambientais (milhares)}

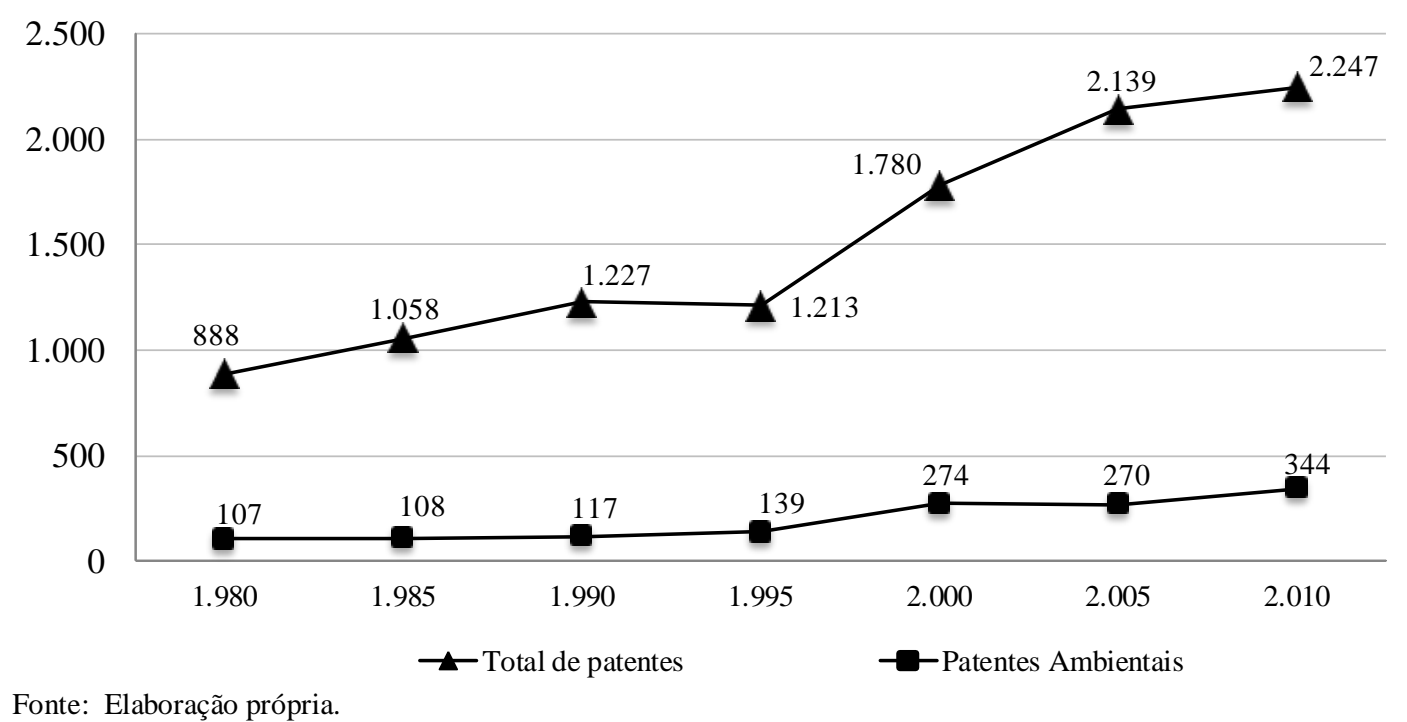

Entre os mais significativos acordos mundiais ${ }^{6}$ que tratam diretamente da mitigação dos impactos ambientais estão: o Protocolo de Montreal (1987, alterado em 1990, 1991 e 1992), que defende a eliminação de clorofluorocarbonetos (CFCs) e halocarbonetos do sistema de produção e processos industriais; a Convenção-Quadro das Nações Unidas sobre as Alterações Climáticas (1992) retrata o impedimento às intervenções humanas que causem danos ao clima global; e, por último, o Protocolo de Kyoto (1997), que defende as reduções de emissões de gases poluentes (de pelo menos $5 \%$ do total de emissões) em países selecionados.

Do mesmo modo, as políticas ambientais e as políticas climáticas obtiveram um significativo impacto sobre as inovações de mitigação climática desde o início dos anos 90 (DECHEZLEPRÊTRE et al., 2011). Além disso, a aceleração tecnológica ambiental no século XXI pode ser interpretada como uma resposta dos agentes inovadores ao Protocolo de Kyoto, implantado efetivamente em 1997. Posteriormente, outros países ratificaram o acordo, estreitando ainda mais a relação entre as políticas climáticas e o aumento do patenteamento das tecnologias ambientais (DECHEZLEPRÊTRE et al. 2011).

Em relação às diferenças entre o patenteamento nos campos das inovações ambientais, a discrepância entre as áreas impressiona, principalmente quanto ao campo 'Produção de Energia Alternativa’ que representa a maior participação (34\%) entre todas as demais áreas tecnológicas (GRÁFICO 2). Em uma análise preliminar, observa-se, no Gráfico 2, que entre as sete áreas tecnológicas verdes por depósitos de patentes de todos os países que englobam o Universo da base de dados, a que mais se destaca entre os anos de 2000 e 2010, refere-se à 'Produção de Energia Alternativa', que obteve um crescimento de 62\% entre os anos supracitados e lidera o ranking em relação às demais áreas. Em seguida, encontram-se as áreas de 'Aspectos Administrativos, Regulatórios e Design’ e de ‘Gestão de Resíduos’ com participação de 22\% e

\footnotetext{
6 Pode-se citar outros exemplos como: a Convenção de Viena (1985); o Protocolo de Helsinki (1985); o Protocolo de Sofia (1988); o Protocolo de Oslo (1994); o Protocolo de Gothenburg (1999), entre outros Protocolos específicos à sua finalidade, seu território e seu período.
} 
17\%, respectivamente, para o ano de 2010. Entretanto, a área de 'Gestão de Resíduos', ao longo de toda a década de 80 até o final da década de 90 , manteve-se com uma produção tecnológica superior à área de ‘Aspectos Administrativos, Regulatórios e Design’ (GRÁFICO 2).

\section{GRÁFICO 2 -Patentes ambientais por classes tecnológicas}

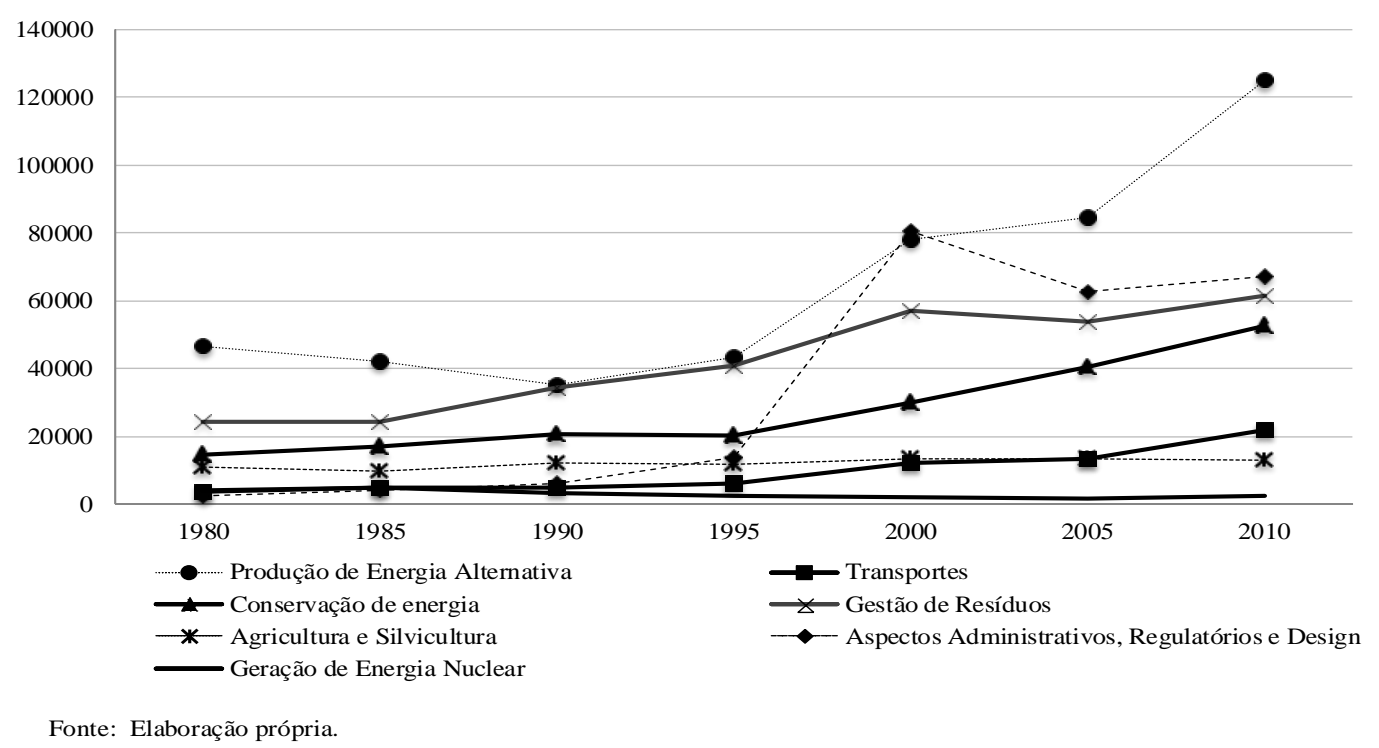

Na área tecnológica de 'Produção de Energia Alternativa', a classe responsável por quase 30\% de toda a participação ao longo dos anos concentrou-se na área de 'Biocombustíveis', seguida da classe tecnológica 'Energia Solar', com 25\% de participação entre todas as tecnologias. De acordo com Haščič et al. (2010), o aumento no patenteamento das tecnologias relacionadas à produção de energia alternativa está intimamente relacionada à introdução do Protocolo de Kyoto. Entre elas, os autores citam além dos biocombustíveis e das tecnologias de energia solar, as tecnologias relacionadas às energias geotérmica e eólica. Além disso, ainda confirmam a importância da associação entre as políticas climáticas globais às políticas tecnológicas, com os fatores associados ao mercado (fatores determinantes ambientais).

\section{Metodologia}

O objetivo do uso das matrizes de interação entre C\&T é identificar quais áreas científicas e tecnológicas, a partir da amostra de países que compõem os grupos BRICS e G7, fomentam o desenvolvimento tecnológico ambiental nos anos de 1990, 2000 e 2010. Além disso, a representação gráfica das matrizes possibilitará diferenciar as características de Sistemas Nacionais de Inovação maduros e imaturos. O conteúdo científico das tecnologias tem aumentado ao longo do tempo, isto é, ele está cada vez mais dependente de suas interações com o desenvolvimento científico. Para a criação das tecnologias ambientais o quadro é semelhante, exigindo-se muitas pesquisas, publicações e estudos científicos entre os agentes e instituições envolvidas. De fato, para a produção de tecnologias ambientais há de se usar intensamente os laboratórios de universidades e institutos de pesquisa. Seria exatamente nesse ponto que o papel dos Sistemas Nacionais de Inovação se enquadra, isto é, presume-se dos SNIs o fortalecimento e o maior envolvimento entre os agentes e instituições em prol do desenvolvimento de novas tecnologias ambientais (MOWERY et al., 2010).

Nesse sentido, a principal contribuição do uso das matrizes seria quanto à representação das informações mais específicas em relação aos campos de ciência e engenharia, relevantes à 
geração da capacidade tecnológica. Em outras palavras, quais áreas de ciência e engenharia são capazes de impulsionar o desenvolvimento tecnológico ambiental. Ademais, os resultados possibilitarão averiguar quais os esforços das nações que possuem Sistemas Nacionais de Inovação imaturos e incompletos, como é o caso do Brasil, Índia, África do Sul em relação ao desenvolvimento e interações entre as áreas científicas e tecnológicas. A análise das configurações desses países possibilitará, sobretudo, identificar aqueles que ao longo dos anos obtiveram um catching up, passando para um estágio superior de interação entre as dimensões científicas e tecnológicas, compatíveis a determinados estágios de capacidade tecnológica dos países desenvolvidos. Outro fator chave inerente à presente metodologia, refere-se à questão qualitativa das patentes. Na metodologia das matrizes de interação C\&T, a qualidade das patentes é um fator preponderante na representação gráfica entre as conexões das áreas de Ciência e Engenharia (C\&E). Sendo assim, a propagação e a robustez das interações entre os campos C\&E e dos domínios tecnológicos mostrados pelas matrizes fornecem informações qualitativas que complementam e enriquecem as informações quantitativas configuradas pelos tradicionais métodos estatísticos de patentes (RIBEIRO et al., 2010).

Em resumo, a ferramenta de análise proposta na metodologia das matrizes visa identificar certas áreas tecnológicas e averiguar quais as áreas de ciência e tecnologia respaldam e apoiam o desenvolvimento das tecnologias ambientais. Entre esses aspectos, é possível elencar alguns elementos significativos, de acordo com os resultados, entre eles:

a) representação gráfica, por intermédio das matrizes, possibilitará diferenciar SNIs maduros e imaturos;

b) abordagens sobre quais países realizaram o processo de catching up, de acordo com os diferentes padrões de desenvolvimentos tecnológicos ambientais entre os países desenvolvidos e em desenvolvimento;

c) identificação de desenvolvimentos tecnológicos ambientais diferenciados e heterogêneos, que poderiam evidenciar certos bloqueios e escassas conexões entre as áreas científicas e tecnológicas de determinados países.

A primeira etapa para a elaboração do conjunto de dados foi realizada pela busca de informações de todas as patentes registradas na base de dados (Patstat). A base de dados do escritório europeu (EPO) conta com as informações de depósitos e registros do próprio escritório e em mais de 30 escritórios pelo mundo, totalizando cerca de 6.142 .400 patentes apenas para os anos de 1990, 2000 e 2010. Para tanto, serão pesquisadas na base de patentes depositadas nos respectivos anos, informações a respeito de cada patente: (a) número da patente na base Patstat; (b) País do primeiro inventor; (c) Classificação Internacional de Patente (IPC); (d) Escritório em que foi depositada a patente; (e) Data do seu depósito; (f) Referências científicas de não patentes. A pesquisa contou, ao todo, com 500.801 patentes ambientais depositadas, que foram extraídas da base de dados Patstat, somente nas autoridades dos países de acordo com a seguinte distribuição: 87.544 (no ano de 1990); 176.458 (em 2000) e 236.799 (em 2010). É válido ressaltar que a riqueza de informações contidas na base EPO permitirá explorar ao máximo todo o conteúdo disponibilizado no momento do depósito de uma patente.

O segundo passo consistiu no tratamento da base de dados, com todas as necessárias adaptações e ajustes referentes aos nomes dos países, assim como seus códigos, completude de todos os campos e verificação das informações extraídas. Por fim, antes da terceira etapa que se caracteriza pela construção das matrizes de interação, foi necessário definir os domínios tecnológicos. Para tanto, utilizou-se um algoritmo que converte o código de classificação tecnológica (classe e subclasse) e o transforma de acordo com os 30 domínios tecnológicos adotados pelo Observatoire des Sciences et des Techniques (OST). ${ }^{7}$

\footnotetext{
${ }^{7}$ As classificações OST e o ISI baseiam-se de acordo com o trabalho de Ribeiro et al. (2010).
} 
Mais especificamente, as interações e as atribuições quanto às classes tecnológicas contidas no processo de registro da patente podem ser convertidas nos subdomínios tecnológicos propostos pelo OST. O texto descrito pela patente também cita artigos científicos publicados em revistas, jornais ou periódicos (indexados ou não), as chamadas referências não-patentes, que permitem identificar as citações usadas para produzir a inovação patenteada.

Para a definição dos campos de Ciência e Engenharia foi desenvolvido um processo mais complexo. O procedimento consistiu na conversão das referências de não-patentes em 27 campos de Ciência e Engenharia (C\&E), definidos pelo Institute for Scientific Information (ISI) e envolveu uma análise léxica (BASSECOULARD; ZITT, 2004). Desse modo, a conversão é configurada entre a área científica definida pelo ISI e a definição associada à palavra-chave ou expressões que caracterizam determinada área, sendo possível a conexão da citação da patente para uma área de ciência e engenharia, quando uma das palavras-chave é obtida no corpo da referência. Portanto, a realização da conexão é estabelecida quando o verbete correspondente a uma área específica definida pelo ISI e o seu "significado" representado por palavras-chave ou expressões que constam no dicionário, configuram-se univocamente o campo de C\&E correspondente.

A interpretação das conexões e interações entre a C\&T é feita a partir de duas conversões (OST e ISI), mediante a identificação de todos os pares de interação entre o subdomínio tecnológico e a área científica. Sendo assim, a identificação correspondente de uma interação entre um subdomínio tecnológico e uma área de ciência e engenharia constitui a célula de uma matriz representada nos gráficos projetados a seguir. Essa interação ocorre de maneira que se o subdomínio tecnológico $X$ interage com a área científica e engenharia $Y$, indicando que para o desenvolvimento da tecnologia específica $X$ houve a necessidade de conhecimento científico desenvolvido na área $Y$. Para uma melhor visualização e interpretação quanto aos resultados das matrizes tecnológicas, será elaborada uma análise quantitativa mais aprofundada, tendo como base os indicadores propostos por Ribeiro et al. (2010). Para tanto, serão elaborados três indicadores: o Índice de Preenchimento da Matriz, o Índice de Rugosidade e a Correlação Intertemporal das matrizes, que serão explicitados individualmente a seguir.

De acordo com o primeiro indicador, será possível demonstrar o nível geral entre as interações de Ciência e Tecnologia em um determinado país. A configuração de uma célula vazia representa a ausência de interação entre um subdomínio tecnológico (OST) e uma disciplina científica (ISI). Com a identificação do nível do preenchimento das matrizes tecnológicas ambientais será possível indicar a capacidade e a diversidade das interações tecnológicas com o peso, ou melhor, a ponderação da ciência para o progresso tecnológico ambiental. Desta forma, o Índice de Preenchimento da Matriz (IPM) será construído da seguinte forma:

$$
F(M)=\sum_{i=1}^{27} \sum_{j=1}^{30} \frac{\delta_{i j}}{27^{*} 30}
$$

em que $\delta_{i j}=0$ se $M_{i j}=0$ ou $\delta_{i j}=1$ se $M_{i j}>0$, e $M_{i j}$ é o número de citações de uma célula da matriz na qual a linha i (representa os subdomínios tecnológicos) e a coluna $j$ (representa as classes científicas). O denominador refere-se ao produto entre o número de colunas e linhas para cada matriz.

O segundo indicador mensura a espessura, o grau de interações sob a superfície da matriz. Este índice é necessário para diferenciar as células não vazias daquelas que contêm qualquer interação, uma vez que podem existir células com apenas uma ou mais de uma citação. Nesse caso, esse indicador combina ambos os níveis de preenchimento das matrizes e o número de citações na matriz. Também chamado como Índice de Rugosidade $(\boldsymbol{\omega})$, sua construção é representada como: 


$$
\omega^{2}(M)=\sum_{i=1}^{27} \sum_{j=1}^{30} \frac{\left(M_{i j}-\bar{M}\right)^{2}}{27^{*} 30}
$$

em que $\boldsymbol{M}_{i j}$ é o número de citações de uma célula da matriz na qual a linha i (representa os

subdomínios tecnológicos) e a coluna j (representa as classes científicas); $\bar{M}$ representa a altura média da matriz e o denominador refere-se ao produto entre o número de colunas e linhas para cada matriz.

Finalmente, o terceiro indicador, denominado como indicador de correlação intertemporal revela a comparação intertemporal entre períodos. Este indicador apresenta ambas as mudanças relacionadas ao nível de preenchimento da matriz, modificações na altura das células e mudanças nos rankings dos picos. O indicador de correlação intertemporal é um meio de organizar as matrizes de uma maneira em que é possível compará-las intertemporalmente, sendo que o objeto desta comparação se refere às superfícies das matrizes. Neste caso, quando duas superfícies das matrizes forem idênticas, a correlação deve ser igual a 1 (um). Quanto mais próximas de 1 (um), mais semelhantes serão, ou seja, mais similares serão seus níveis de preenchimento da matriz, a altura das células da matriz e a localização dos picos de determinada matriz. A correlação intertemporal entre as matrizes é o coeficiente de correlação $R_{M, M^{\prime}}$, entre as interações de ciência e tecnologia das matrizes M e M’:

$$
R_{M, M}=\sum_{i=1}^{27} \sum_{j=1}^{30} \frac{\left(M_{i j}-\bar{M}\right)\left(M_{i j}^{\prime}-\bar{M}^{\prime}\right)}{\omega(M)^{*} \omega\left(M^{\prime}\right)}
$$

Em resumo, os três indicadores apresentam importantes configurações a respeito dos resultados das matrizes ano a ano: $1^{\circ}$ a estrutura da matriz tecnológica ambiental (preenchimento, altura e grau de interações tecnológicas e científicas); $2^{\circ}$. dinâmica e evolução das capacidades ambientais ao longo do tempo. O foco da aplicação da metodologia de matrizes de interação entre ciência e tecnologia (C\&T), baseada nos algoritmos desenvolvidos por Ribeiro et al, 2010, será investigar as interações entre as áreas de C\&T, através da introdução da classificação de patentes ambientais. Nesse sentido, a metodologia tem por objetivo identificar a natureza das relações entre ciência e tecnologia ambiental nos diversos SNIs, isto é, relacionar e investigar as interações e assimetrias tecnológicas. A partir dessas assimetrias, será possível observar qual o peso da ciência para o progresso tecnológico ambiental e para as bases científicas nacionais.

Do mesmo modo, a partir das análises das matrizes de interação de C\&T, será possível perceber a evolução e o desempenho do conteúdo científico e tecnológico das inovações ambientais ao longo do tempo. Em outras palavras, busca-se extrair e identificar quais as interações e subdomínios tecnológicos relevantes ao desenvolvimento tecnológico ambiental nos grupos BRICS e G7, no período analisado. A elaboração das matrizes permitirá expor os desafios tecnológicos ambientais colocados tanto para as nações desenvolvidas quanto para as economias em desenvolvimento nas últimas três décadas.

\section{Discussão de resultados}

As matrizes tecnológicas do grupo BRICS para o ano de 1990 (Tabela 1) obtiveram um processo de preenchimento incompleto, isto é, nenhuma das células das matrizes foi preenchida. Esse processo significa dizer que não houve relacionamento entre o patenteamento ambiental com as citações nas disciplinas de Ciência e Engenharia (C\&E) no referido ano. Nesse caso, pode-se considerar o fato de que a discussão sobre inovações ambientais e a disseminação das questões sobre mudanças climáticas naquele ano eram ainda muito incipientes nessas nações. Contudo, tais resultados são bem diferentes quando comparados aos Sistemas Nacionais de 
Inovação mais maduros e fortalecidos, presentes nos grupos dos países que englobam o G7, como podem ser observados pela Figura 1.

TABELA 1 - Indicadores de desempenho das matrizes tecnológicas ambientais (1990)

\begin{tabular}{clccc}
\hline \multirow{2}{*}{ Grupo País } & Total Citações & $\begin{array}{c}\text { Índice de } \\
\text { Preenchimento }\end{array}$ & $\begin{array}{c}\text { Índice de } \\
\text { Rugosidade }\end{array}$ \\
\hline \multirow{3}{*}{ BRICS } & Brasil & 0 & $0,0 \%$ & 0 \\
& Rússia & 0 & $0,0 \%$ & 0 \\
& Índia & 0 & $0,0 \%$ & 0 \\
& China & 0 & $0,0 \%$ & 0 \\
& África do Sul & 0 & $0,0 \%$ & 0 \\
& Alemanha & & & 0,24 \\
& Canadá & 1.326 & $28,6 \%$ & 0,05 \\
& Estados Unidos & 236 & $7,7 \%$ & 5,01 \\
& França & 39.809 & $74,2 \%$ & 0,25 \\
& Itália & 1.789 & $38,1 \%$ & 0 \\
& Japão & 0 & $0,0 \%$ & 0,08 \\
& Reino Unido & 357 & $12,8 \%$ & 0,1 \\
\hline
\end{tabular}

Fonte: Elaboração própria.

Nesse ponto, a ferramenta de análise representada pelas matrizes permite focalizar quais subdomínios e quais áreas científicas apoiam e corroboram para o desenvolvimento tecnológico ambiental. Do mesmo modo, as questões que envolvem soluções alternativas aos problemas ambientais, exigem dos países não somente o desenvolvimento da capacidade tecnológica, mas principalmente, o fortalecimento de seus Sistemas Nacionais de Inovação.

É válido ressaltar que as oportunidades e a acumulação de vantagens tecnológicas devem ser consideradas também pelos diferenciais existentes entre os países avançados e os menos desenvolvidos, principalmente pelo processo de difusão de inovações, incluindo a imitação e as transferências de tecnologias. Estas últimas são mais propícias de ocorrerem nos países em desenvolvimento (DOSI et al., 1990). Nesse caso, seria exatamente nesse contexto sobre a evolução dos resultados da acumulação tecnológica de todas as melhorias e esforços, que é reconhecido o desenvolvimento das trajetórias tecnológicas existentes nos Sistemas Nacionais de Inovação.

No ano de 1990, o grupo dos países que compõem o G7, com exceção da Itália, apresentou relevantes interações entre os pares de subdomínio tecnológico e área científica, além de demonstrar um nível de preenchimento bem distinto quando comparado ao grupo do BRICS (Tabela 1). Pela Figura 1, é possível notar que os Estados Unidos possuem o maior pico de interação correspondente ao par subdomínio tecnológico 9 ‘Químicas Finas Orgânicas’ e área científica 6 'Química Inorgânica e Engenharia'. Este país tem grande parte da interação concentrada nos subdomínios 9, 12 e 20 e áreas científicas 3, 6 e 13, sendo subdomínios e áreas bastante semelhantes às faixas pertencentes a países como o Japão, Canadá e Alemanha. Comparando-se as matrizes da França com as da Alemanha, países nos quais os índices de preenchimento e rugosidade são bastante similares, ambas apresentaram matrizes com interações esporádicas e escassas, nas quais os picos de interação concentram-se no subdomínio 7 (Análise, Mensuração e Controle) e área científica 6 (Química Inorgânica e Engenharia), sendo que a Alemanha desponta também para os subdomínios tecnológicos mais relacionados ao meio ambiente como o OST 20 'Meio Ambiente e Poluição, o que parece indicar que a Alemanha promoveu o desenvolvimento mais especificamente deste subdomínio tecnológico no ano de 1990. 



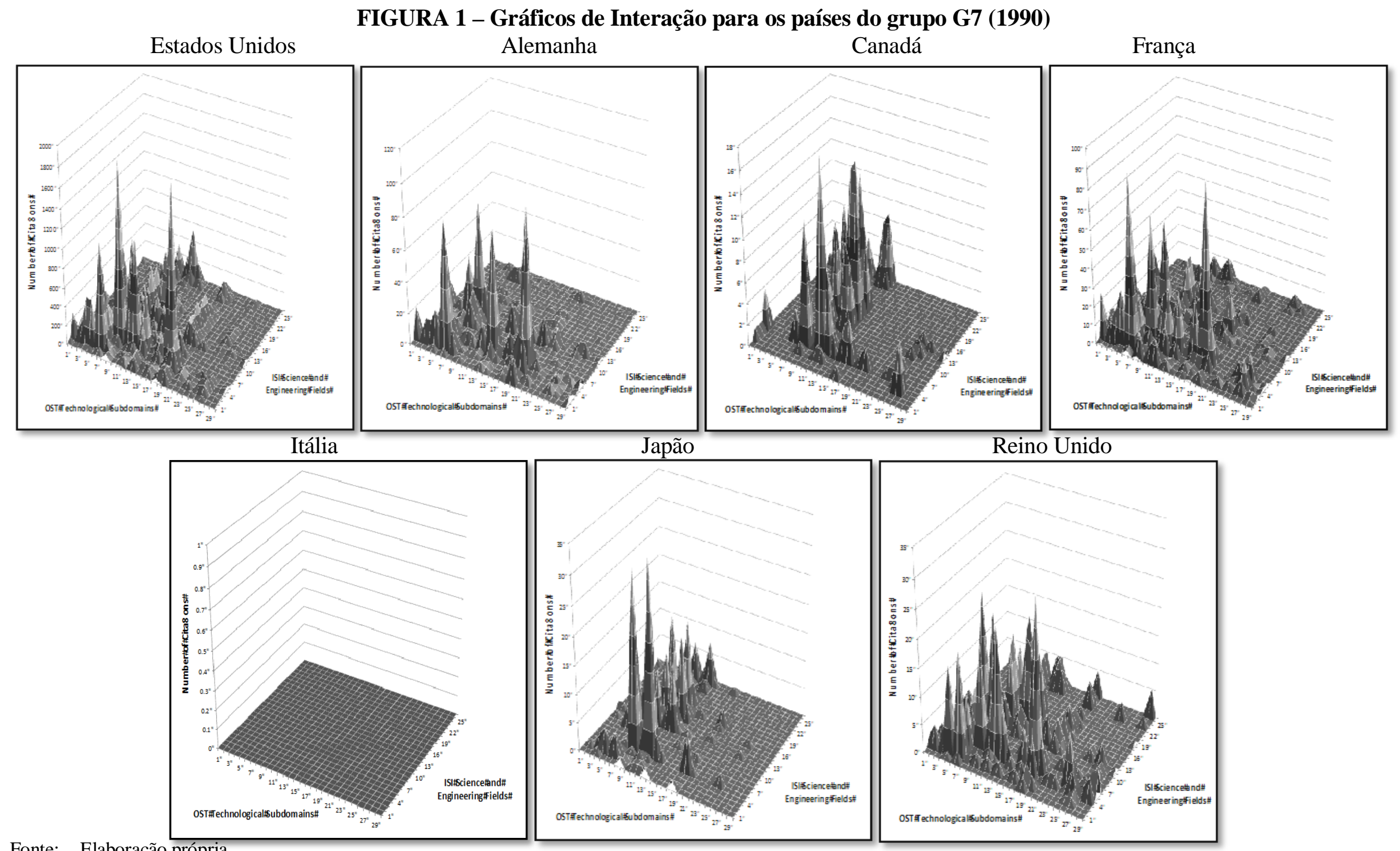

Fonte: Elaboração própria. 
Quanto ao ano 2000, visualiza-se uma pequena evolução quanto às matrizes de interação do grupo BRICS, que obtiveram um fortalecimento de interações entre C\&T, no qual essas combinações podem ser identificadas por uma distribuição de células preenchidas. A Figura 2 e a Tabela 2 apontam que o desenvolvimento tecnológico ambiental nos países em desenvolvimento evoluiu em comparação ao comportamento do mesmo grupo no ano de 1990. Em geral, cada país do grupo BRICS representa níveis diversos de desenvolvimento com diferentes regimes entre $C \& T$ e capacidades tecnológicas ambientais. Além disso, a lacuna existente entre essa capacidade tecnológica ambiental entre os países desenvolvidos e em desenvolvimento é bastante visível, como mostram os resultados dos indicadores na Tabela 2, em que o país de maior citação entre os países em desenvolvimento, a Índia tem o padrão similar de interações referente ao último país do ranking do grupo G7, a Itália.

Entre os subdomínios tecnológicos, os campos 12 'Biotecnologia' e 26 'Produtos agrícolas e alimentícios’, e as áreas científicas 6 'Química Inorgânica e Engenharia’ e 14 'Ecologia' obtiveram elevados pesos e contribuíram para a incidência dos picos de interação, principalmente na Índia. Já o grupo dos países desenvolvidos, o G7, a Figura 3 e a Tabela 2 indicam que houve uma mudança quanto ao preenchimento das células das matrizes, que de certa forma, tornaram-se mais homogêneas e uma movimentação das interações de C\&T que, nos últimos dez anos, predominaram nos domínios e áreas científicas concentradas no campo da Química e Meio Ambiente. A magnitude das interações da economia americana ainda é proeminente se comparada às maiores potências mundiais, cuja década os Estados Unidos diversificaram seus principais pontos de interação. No ano 2000, o país desviou o seu foco também para o subdomínio científico 11 'Farmacêuticos e Cosméticos' e para áreas científicas ligadas à saúde, 18 'Biologia Geral' e 26 'Pesquisa Médica', seguindo a tendência mundial verificada na configuração das matrizes globais.

TABELA 2 - Indicadores de desempenho das matrizes tecnológicas ambientais (2000)

\begin{tabular}{llcccc}
\hline Grupo & \multicolumn{1}{c}{ País } & Total Citações & $\begin{array}{c}\text { Índice de } \\
\text { Preenchimento }\end{array}$ & $\begin{array}{c}\text { Índice de } \\
\text { Rugosidade }\end{array}$ & $\begin{array}{c}\text { Correlação } \\
(1990-2000)\end{array}$ \\
\hline \multirow{2}{*}{ BRICS } & Brasil & 9 & $0,7 \%$ & 0 & - \\
& Rússia & 5 & $0,6 \%$ & 0 & - \\
& Índia & 122 & $5,4 \%$ & 0,03 & - \\
& China & 27 & $1,6 \%$ & 0,01 & - \\
& África do Sul & 38 & $3,3 \%$ & 0,01 & - \\
& & & & & 0,57 \\
& Alemanha & 1.502 & $30,6 \%$ & 0,21 & 0,66 \\
& Canadá & 1384 & $25,8 \%$ & 0,2 & 0,73 \\
& Estados Unidos & 22.394 & $57,3 \%$ & 3,13 & 0,78 \\
& França & 3.793 & $44,8 \%$ & 0,41 & - \\
& Itália & 67 & $5,4 \%$ & 0,01 & 0,88 \\
& Japão & 2431 & $29,9 \%$ & 0,42 & 0,65 \\
\hline
\end{tabular}

Fonte: Elaboração própria.

Observou-se também que grande parte das nações direcionou seus esforços no subdomínio tecnológico 12 'Biotecnologia' e na área científica 18 'Biologia Geral'. Com exceção da Alemanha, que ao contrário da última década, investiu sua capacidade tecnológica em subdomínios mais relacionados ao campo de meio ambiente. No ano 2000, os picos de interação foram mais direcionados às áreas de engenharia e química, como os subdomínios 5 'Semicondutores', 1 'Componentes Elétricos' e áreas científicas relacionadas à 3 'Engenharia Eletrônica’ e 6 ‘Química Inorgânica e Engenharia’. 
Brasil Rússia

Índia
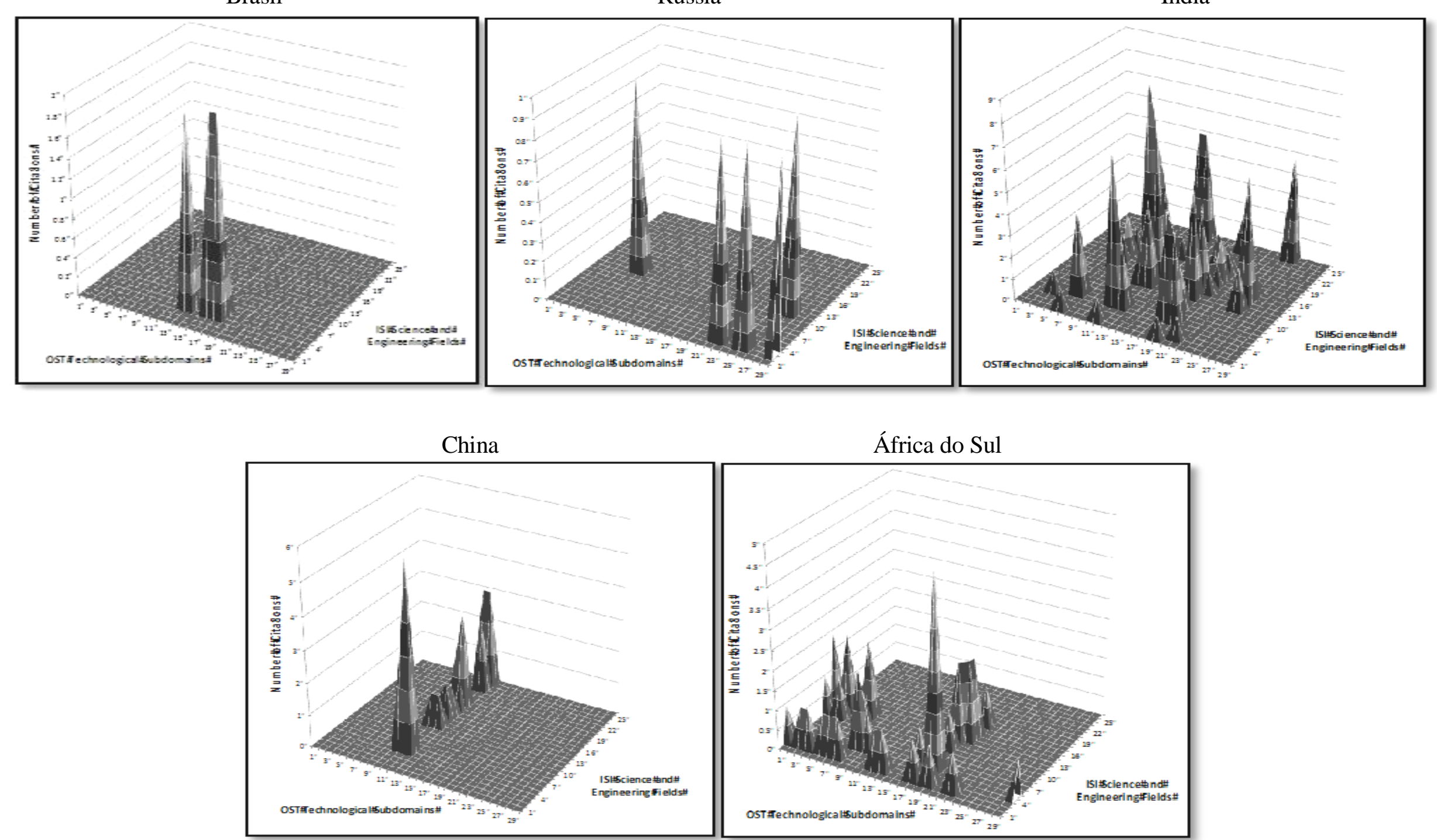
FIGURA 3 - Gráficos de Interação para os países do grupo G7 (2000)

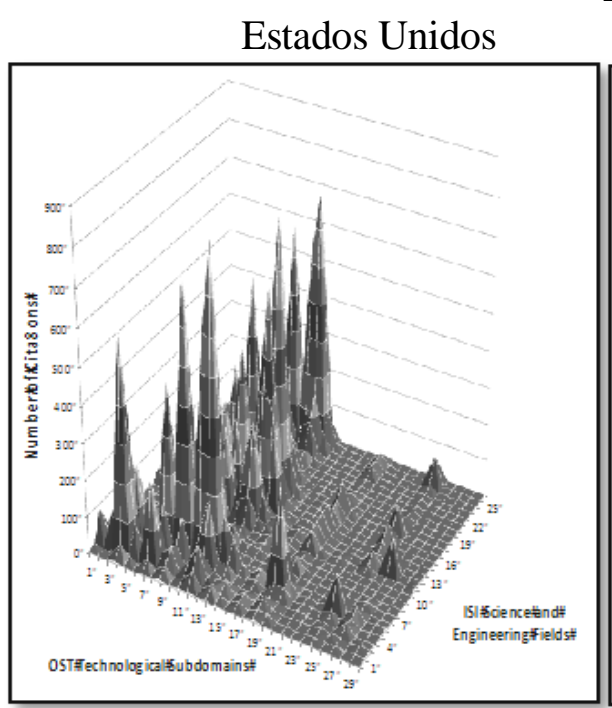

Alemanha

Canadá

França
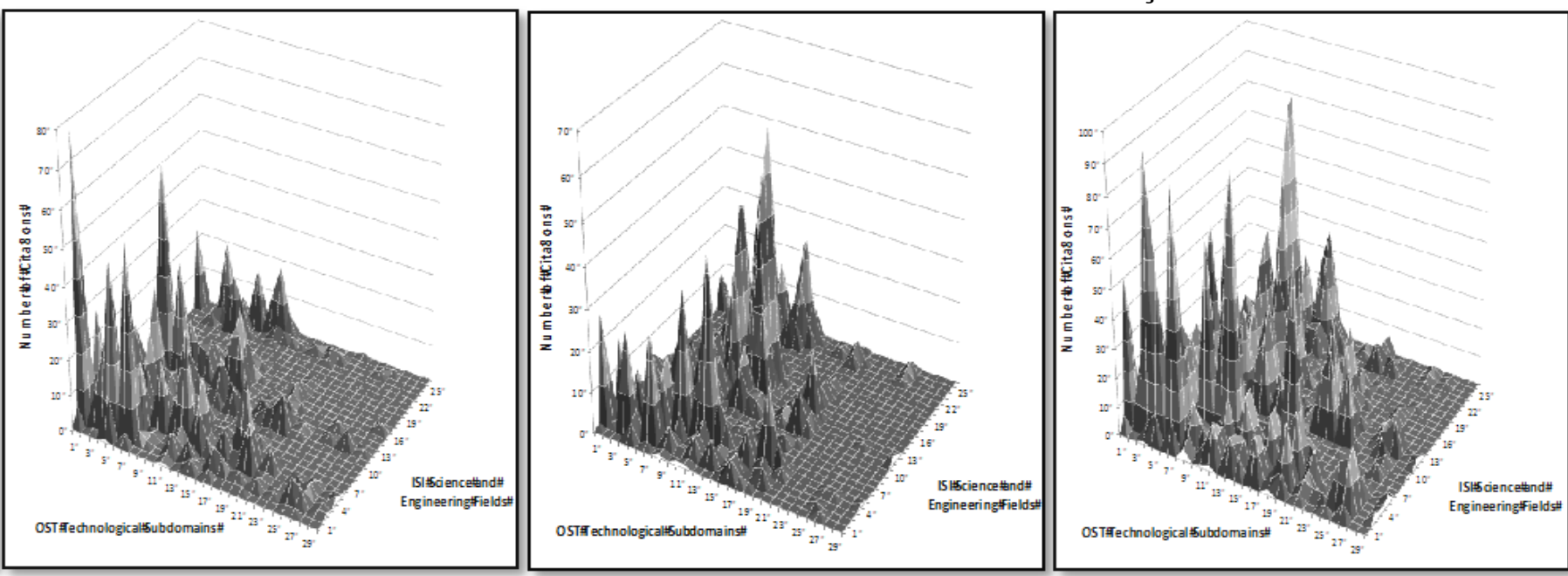

Itália

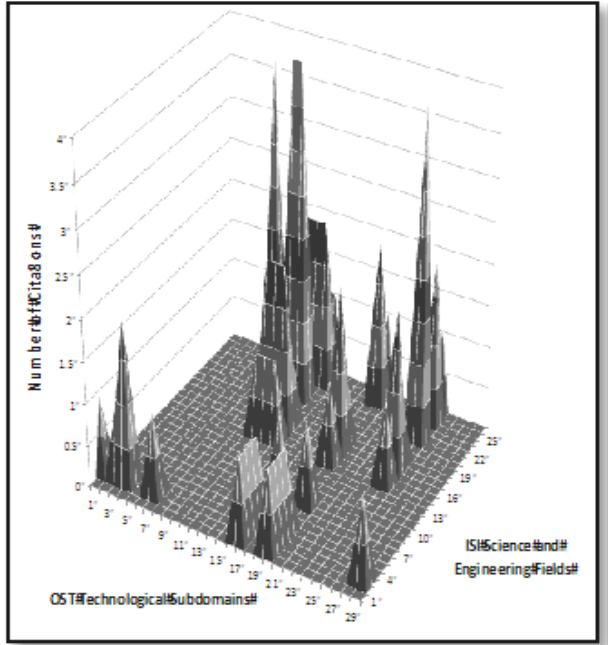

Japão

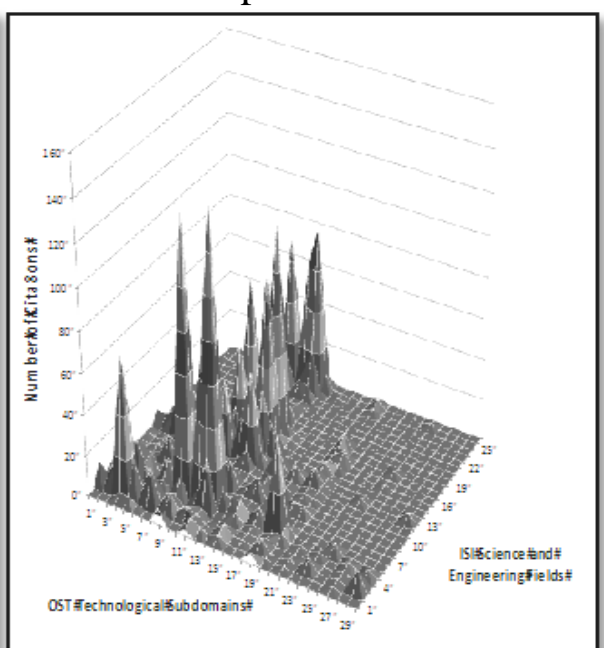

Reino Unido

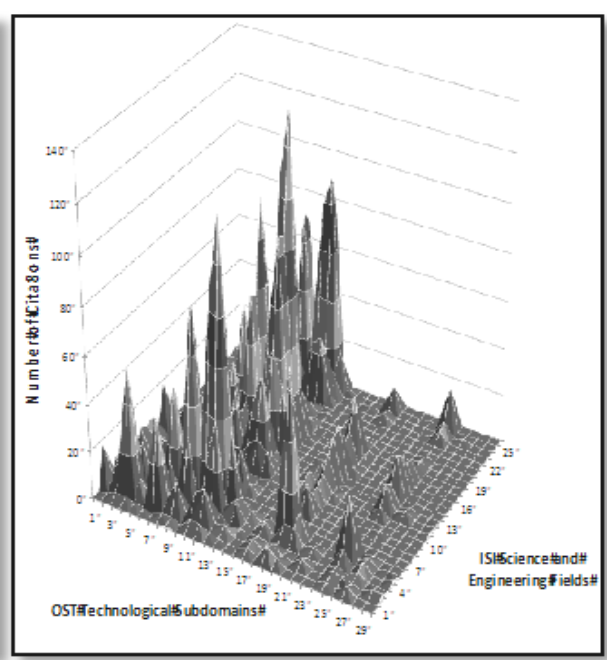

Fonte: Elaboração própria. 
Quanto aos indicadores de desempenho das matrizes, a Tabela 2 mostra a preponderância em relação ao preenchimento das células das matrizes do grupo G7 vis à vis ao índice de preenchimento do grupo BRICS. Como explicitado anteriormente, os picos apresentados em 1990 não foram os mesmos picos de interação visualizados no ano 2000, e a correlação intertemporal entre os anos não foi muito elevada, com exceção do valor apresentado no Japão. O índice de rugosidade também foi baixo, com exceção do índice para os Estados Unidos ${ }^{8}$. O resultado deste índice revela que a complexidade e a ampla rede de interações científicas e tecnológicas existente no grupo G7 é fundamental para o desenvolvimento das tecnologias ambientais e para a construção de Sistemas Nacionais de Inovação fortalecidos.

Por fim, no último ano, de acordo com a Figura 4, é possível observar que os países do grupo BRICS obtiveram um grande aumento no preenchimento da área das matrizes e, certamente, as mudanças entre os campos nos subdomínios tecnológicos e áreas científicas, durante as últimas décadas (1990 e 2000), provocaram essa expansão e diversificação das interações entre a C\&T. No ano de 2010, como podem ser observadas na Figura 4 e na Tabela 3 , as matrizes tecnológicas do grupo BRICS ainda apresentam baixos índices de preenchimento e mudanças em seus domínios tecnológicos e áreas científicas líderes. Ao contrário dos campos líderes analisados no ano 2000, houve uma mudança no perfil de interações entre C\&T nos últimos dez anos.

TABELA 3 - Indicadores de desempenho das matrizes tecnológicas ambientais (2010)

\begin{tabular}{llcccc}
\hline Grupo & \multicolumn{1}{c}{ País } & Total Citações & $\begin{array}{c}\text { Índice de } \\
\text { Preenchimento }\end{array}$ & $\begin{array}{c}\text { Índice de } \\
\text { Rugosidade }\end{array}$ & $\begin{array}{c}\text { Correlação } \\
(1990-2000)\end{array}$ \\
\hline \multirow{2}{*}{ BRICS } & Brasil & 225 & $11,2 \%$ & 0,04 & 0,14 \\
& Rússia & 122 & $6,5 \%$ & 0,03 & 0,01 \\
& Índia & 945 & $18,8 \%$ & 0,14 & 0,46 \\
& China & 991 & $28,0 \%$ & 0,12 & 0,24 \\
& África do Sul & 81 & $2,3 \%$ & 0,03 & 0,17 \\
& & & & 0,58 & 0,79 \\
& Alemanha & 4.312 & $45,6 \%$ & 0,1 & 0,64 \\
& Canadá & 795 & $23,2 \%$ & 3,77 & 0,73 \\
& Estados Unidos & 29.040 & $68,4 \%$ & 0,51 & 0,71 \\
& França & 4.620 & $47,4 \%$ & 0,05 & 0,07 \\
& Itália & 156 & $6,7 \%$ & 1,3 & 0,78 \\
& Japão & 9616 & $51,0 \%$ & 0,6 & 0,5 \\
\hline
\end{tabular}

Fonte: Elaboração própria.

Com exceção do subdomínio tecnológico 12 'Biotecnologia', que representa uma tendência tecnológica mundial em ambos os grupos, os campos tecnológicos lideres entre os países abrangem os campos 19 'Processamento Químico Básico’, 9 'Químicas finas orgânicas', 11 'Farmacêuticos e cosméticos'. Ainda que os subdomínios apresentem poucas interações é possível captar as movimentações e a tendência quanto aos domínios tecnológicos no grupo BRICS.

\footnotetext{
8 Narin et al. (1997) ressalta as vantagens dos investimentos governamentais em ciência para o avanço tecnológico em determinados setores industriais nos EUA. O sucesso para o desenvolvimento tecnológico no país é respaldado pela ciência básica que atuou como peça chave nos resultados da alta tecnologia nacional.
} 


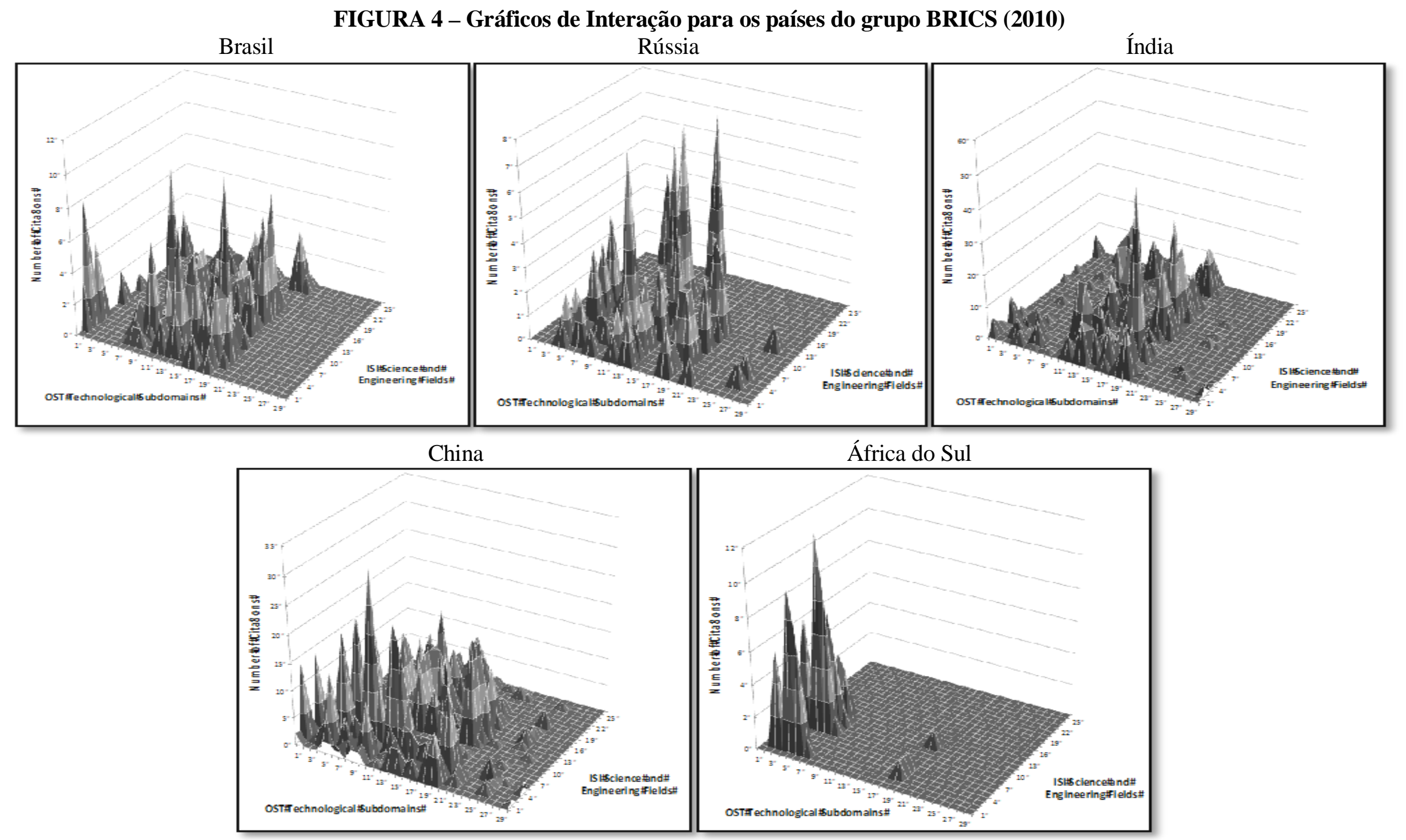

Fonte: Elaboração própria. 
Em relação aos campos científicos, as áreas de Química e Engenharias dominam o conjunto de interações, não sendo muito discrepantes quanto aos resultados verificados no ano 2000.

Em relação aos países do grupo G7, ao contrário dos indicadores referentes aos países em desenvolvimento, a Figura 5 e a Tabela 3 exibem um elevado índice de preenchimento em todas as economias, principalmente nos Estados Unidos, com cerca de 70\% de propagação de células preenchidas. Em 2010, diferentemente dos países do grupo BRICS, os países do grupo G7 não diversificaram substancialmente seus subdomínios tecnológicos considerados líderes, em relação ao ano de 1990. Os subdomínios relacionados à 19 'Farmacologia e Farmácia', 9 'Química Orgânica', além da 12 'Biotecnologia' foram preponderantes no que concerne aos demais campos tecnológicos. Já em relação às áreas científicas, aquelas que sobressaíram em relação às demais foram a 6 'Química Inorgânica e Engenharia, 3 'Engenharia Eletrônica'. Do mesmo modo, o destaque das áreas científicas em 2010 concentra-se no âmbito da área 16 'Biotecnologia' que dominou grande parte dos campos científicos dos países do grupo. Por ser uma área tecnológica considerada como 'fronteiriça', a Biotecnologia, ao longo das três décadas, indicou evidências que o aumento das interações nesse campo reflete as mudanças nos paradigmas, indicando também o direcionamento subjacente à trajetória tecnológica ambiental.

Sob esse ponto de vista, ressalta-se também que as análises das matrizes de interação entre C\&T são complexas e envolvem questões inerentes ao processo de interação, como, por exemplo, as competências tecnológicas ambientais de cada nação, que exigem aprofundamento e investigação entre suas relações econômicas e setoriais. No entanto, todos os campos tecnológicos e áreas científicas supracitadas são fontes de pesquisa importantes, no qual se revelou expressivas assimetrias e desigualdades em diversos aspectos, tanto quanto ao número total de citações quanto às diversidades em termos de interação da C\&T.

Observou-se, ainda, que o desenvolvimento da capacidade tecnológica dos países, tanto do grupo G7 quanto do grupo BRICS envolve processos de aprendizados distintos. Em outras palavras, a trajetória tecnológica ambiental observada ao longo das três décadas entre os países seria uma trajetória de aprendizados cumulativos, em que os padrões tecnológicos vigentes são mais flexíveis de serem modificados a longo prazo, o que foi observado pelas mudanças entre os domínios e áreas científicas das matrizes. Tal resultado é um produto da capacidade tecnológica e de aprendizados dos países ao longo dos anos, e determina o quão adequadamente cada nação é capaz de lidar com as novas tecnologias (KIM; NELSON, 2005). Além dos aspectos apresentados, as principais características das economias desenvolvidas são relacionadas à sua significância quanto ao setor industrial. Mais especificamente, quando se renova e amplia a base tecnológica em setores como nanotecnologia, biotecnologia e outros relacionados à tecnologias limpas, há um maior dinamismo interno, surgindo assim maior capacidade e melhoria de absorção do conhecimento, além de viabilizar o processo de catch-up (ALBUQUERQUE, 2009). Nesse sentido, a condição de dependência em relação aos países desenvolvidos não é mais um fator preponderante quando se compara os países mais avançados com os atrasados tecnologicamente (PEREZ, 2014).

A afirmativa é pautada no apoio tecnológico dado pelo Estado e seu papel forte e atuante nos investimentos relacionados à capacidade tecnológica nacional. A China, por exemplo, é um país que foi privilegiado pelo processo de catching-up bem avançado em relação à setores como tecnologia da informação e comunicação e energias alternativas. Outros países como o Brasil e a Índia tem testemunhado o avanço de empresas líderes globais e inovativas em setores como de Biotecnologia. (PEREZ, 2014). Nesse sentido, o que é comum em relação ao processo de catching up e as teorias atuais sobre os SNIs é que a participação do Estado neste processo é crucial, tanto na execução quanto na coordenação das políticas de médio e longo prazo, para o desenvolvimento da indústria ou de setores tecnológicos específicos. 

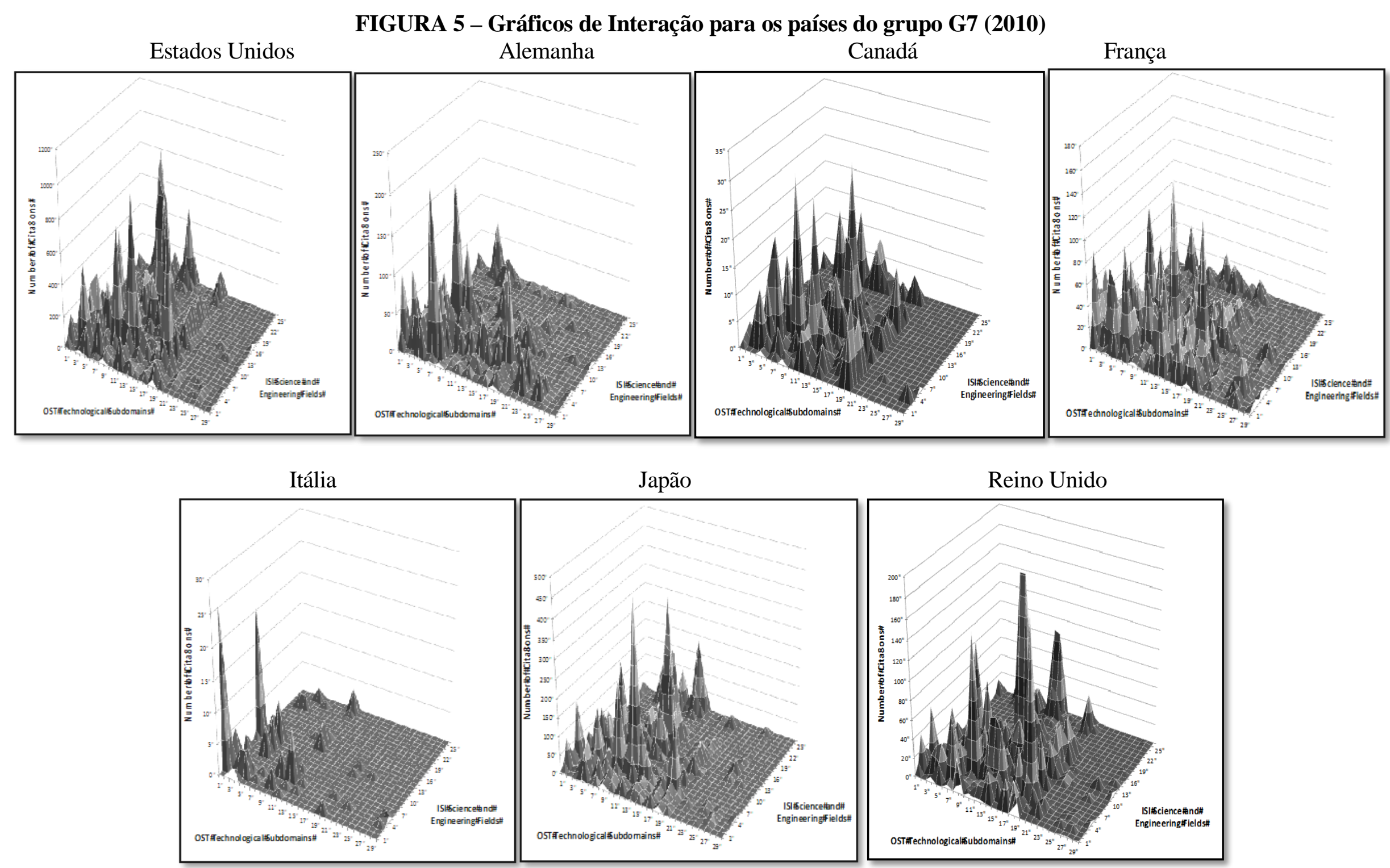

Fonte: Elaboração própria. 


\section{Conclusões}

A interpretação e a análise das matrizes de interação de C\&T buscaram compreender como a trajetória tecnológica ambiental evoluiu ao longo das três décadas. Torna-se oportuno ressaltar a natureza do impacto das inovações ambientais sobre as interações científicas e tecnológicas neste período. Os resultados apresentaram duas vertentes relevantes na lógica sobre a evolução das interações entre C\&T. A primeira refere-se às matrizes tecnológicas do grupo G7 que se direcionaram mais para subdomínios e áreas próximas aos paradigmas apresentados pelas matrizes globais e campos similares à fronteira tecnológica, como 0 campo da Biotecnologia. A segunda vertente constituiu-se na percepção de que os países do grupo BRICS ainda buscam se consolidar em áreas onde os países desenvolvidos já possuem largamente o conhecimento tecnológico e científico, que seriam as áreas de ‘Semicondutores’, ‘Telecomunicações’ e ‘Ótica’.

Entre os países do grupo BRICS, a China e a Îndia destacaram-se ao longo do período em análise, não somente pelo desempenho e qualidade dos seus subdomínios tecnológicos e campos científicos, mas também pelo aumento da quantidade de citações, principalmente em relação aos anos de 2000 e 2010, com crescimento de $87,08 \%$ e $97,28 \%$, respectivamente. O processo observado pode ser também considerado como um 'retrato' do processo de catching up da capacidade tecnológica ambiental entre o período de 10 (dez) anos. A China e a Índia possuem setores industriais diversificados e padecem de sérias defasagens tecnológicas, mas ainda se sobressaltam quanto as suas dimensões de mercado interno e inovação em novas tecnologias (KIM; NELSON, 2005). O que se observou ao longo do período foi que o contexto atual, com imposições a metas de emissões e produções de fontes energéticas menos dependentes de combustíveis fósseis, induziram, de certa forma, esses países a traçar novas estratégias ambientais. Em geral, as capacidades tecnológicas ambientais nos países em desenvolvimento foram observadas suavemente, mas não enfraquecem a importância de maiores investimentos em sua infraestrutura econômica, social e científica.

Em relação aos países desenvolvidos, observou-se que ao longo do tempo, a evolução e o desempenho das interações entre a C\&T são fatores inerentes ao seu processo de aprendizagem, isto é, dependem muito mais da trajetória tecnológica dos países. Logo, as mudanças tecnológicas em direção ao desenvolvimento das tecnologias ambientais são factíveis, porém as mesmas são condicionadas às inovações e tecnologias geradas em períodos anteriores. O papel do aprendizado tecnológico é profundamente específico à determinada tecnologia e às interações tecnológicas encontradas, dado que cada tecnologia demanda específicos graus de exigências de aprendizado.

Nesse sentido, entende-se que os países se sujeitam a períodos de aprendizados incertos, difíceis e prolongados, dependendo, é claro, do nível de conhecimento e aprendizado cumulativo. A introdução de novas tecnologias, isto é, tecnologias limpas, ambientais, envolvem uma diversidade de aprendizados, desde a interação entre as firmas e setores, firmas e consumidor e instituições de pesquisa e firmas. Entende-se que essa diversidade e as assimetrias de aprendizados entre os países englobam também questões multidisciplinares, como a infraestrutura tecnológica, econômica e científica, as questões culturais e educacionais, a qualidade da Pesquisa e Desenvolvimento (P\&D), a qualificação da mão de obra e outros fatores essenciais para o desenvolvimento e progresso dos Sistemas Nacionais de Inovação, como um todo.

Destarte, o desenvolvimento tecnológico ambiental dos países dependerá de esforços e aptidões em todos os níveis, desde o chão de fábrica, passando pela engenharia de produtos e processos e as relações entre universidades, instituições de pesquisa e firmas. Os incentivos para a produção, pesquisas e desenvolvimento das tecnologias ambientais dependerão não somente da capacidade tecnológica de cada país, mas essencialmente, de questões regulatórias, políticas e setoriais que visam à mitigação dos impactos ambientais, nos quais as evidências sugerem uma forte correlação entre os gastos e investimentos com a redução da poluição e o fomento de tecnologias ambientais.

\section{Referências Bibliográficas}

ALBUQUERQUE, E. M. Catching up no século XXI: construção combinada de sistemas de inovação e de bem estar social. In: SICSÚ, J., MIRANDA, P. C. Crescimento Econômico: Estratégias e Instituições. Rio de Janeiro: Ipea, 2009. cap. 3, p. 55-84. 
BASSECOULARD, E., ZITT, M. Patents and publications: the lexical connection. In: MOED, H. F., GLÄNZEL, W., SCHMOCH, U. Handbook of quantitative Science and technology research: the use of publication and patent statistics in studies of S\&T systems. Dordrecht: Kluwer Academic Publishers, 2004, Chapter 30, p. 665-694. DECHEZLEPRÊTRE, A., GLACHANT, M., HĂSČIČ, I., JOHNSTONE, N., MÉNIÉRE, Y. Invention and Transfer of Climate Change-Mitigation Technologies: A Global Analysis. Review of Environmental Economics andPolicy, v. 5, n.1, p. 109-130, 2011.

DOSI,G., PAVITT, K., SOETE, L. The Economics of Technical Change and Intemational Trade. Brighton: Wheatsheaf, 1990.

FREEMAN, C., SOETE, L. A economia da inovação industrial. Campinas: Editora da Unicamp, 2008. GOMEZ, J. M., CHAMON, P. H., LIMA, S. B. Por uma nova ordem energética global? Potencialidades e perspectivas da questão energética entre os países BRICS. Contexto Internacional. Rio de Janeiro, v. 34, n.2, p.531596, 2012.

HĂSČČC, I., JOHNSTONE, N., WATSON, F., KAMINKER, C. Climate Policy and Technological Innovation and Transfer: na overview of trends and recent empirical results. OECD Environment Working Paper, n. 30, OECD Publishing, 2010.

JOHNSTONE, N., HĂSČIČ́, I., OSTERTAG, K. Environmental Policy, Technological Innovation and Patent Activity. OECD Studies on Environmental Innovation. OECD Publishing, Paris, 2008.

KIM, L., NELSON, R. R., Tecnologia, aprendizadoe inovação: as experiências das economias de industrialização recente. Editora Unicamp, 2005.

LANJOUW, J. O., MODY, A. Innovation and the intemational diffusion of environmentally responsive technology. Research Policy, v. 25, p. 549-571, 1996.

MOWERY, D. C., NELSON, R. R., MARTIN, B. R. Technologypolicy and global waming: Why new policy models are needed (or why putting new wine in old bottler won’t work). Research Policy. v. 39, n. 8, p. 1011-1023, 2010.

NARIN, F., HAMILTON, K. S., OLIVASTRO, D. The increasing linkage between U.S. technology and public science. Research Policy. V.26, n.3, p. 317-330, 1997.

OECD. Measuring Globalisation. OECD Economic Globalisation Indicators 2010. Organization for Economic Co-Operation and Development . Disponível em: http://unstats.un.org/unsd/EconStatKB/Attachment550.aspx. Acesso em: 14 fev. 2015.

PEREZ,C. A green and socially equitable direction for the ICT Paradigm. The global network for economics of learning innovation and competence. Working Paper Series-Globelics. N. 2014-01, ISSN: 2246-0616. 2014. REENINGS, K. Redefining innovation-eco-innovation research and the contribution from ecological economics. Ecological Economics, v. 32, n. 2, p. 319-332, 2000.

RIBEIRO, L. C., RUIZ, R. M., BERNARDES, A. T., ALBUQUERQUE, E. M. Matrices of science and technology interactions and pattems of structured growth: implications for development. Scientometrics. v. 83, n. 1, p. 55-75., 2010.

TGCII. The Global Cleantech Innovation Index. Nurturing Tomonow's Transformative Entrepreneurs. 2014.Disponível<http://awsassets.wwf.org.za/downloads/wwf_report_global_cleantech_innovation_index_2014 final_.pdf>. Acesso em: 11 de julho de 2014.

VANDER BERGH, J.Handbook of Environmental and Resource Economics. Cheltenham and Northampton: Edward Elgar, 1999.

WINDRUM, P., CIARLI, T., BIRCHENHALL, C. Consumer heterogeneity and the development of environmentally friendly Technologies. Technological Forecasting and Social Change. v. 76, n. 4, p. 533-551, 2009. 